University of Louisville

ThinkIR: The University of Louisville's Institutional Repository

$5-2013$

\title{
"This is not what motherhood looks like" : mothers' interpretations of cultural representations of the celebrity pregnant and post- partum body.
}

Brittany M. Williams 1987-

University of Louisville

Follow this and additional works at: https://ir.library.louisville.edu/etd

\section{Recommended Citation}

Williams, Brittany M. 1987-, "'This is not what motherhood looks like" : mothers' interpretations of cultural representations of the celebrity pregnant and post-partum body." (2013). Electronic Theses and Dissertations. Paper 1576.

https://doi.org/10.18297/etd/1576

This Master's Thesis is brought to you for free and open access by ThinkIR: The University of Louisville's Institutional Repository. It has been accepted for inclusion in Electronic Theses and Dissertations by an authorized administrator of ThinkIR: The University of Louisville's Institutional Repository. This title appears here courtesy of the author, who has retained all other copyrights. For more information, please contact thinkir@louisville.edu. 
"THIS IS NOT WHAT MOTHERHOOD LOOKS LIKE": MOTHERS' INTERPRETATIONS OF CULTURAL REPRESENTATIONS OF THE CELEBRITY PREGNANT AND POST-PARTUM BODY

by

\title{
BRITTANY M. WILLIAMS
}

\author{
A Thesis \\ Submitted to the Faculty of the \\ College of Arts and Sciences of the University of Louisville \\ in Partial Fulfillment of the Requirements \\ for the Degree of
}

Masters of Arts

Department of Women's and Gender Studies

University of Louisville

Louisville, Kentucky

May 2013 
Copyright by Brittany Marie Williams

All rights reserved 
'This is Not What Motherhood Looks Like': Mothers' Interpretations of Cultural Representations of the Celebrity Pregnant and Post-Partum Body

By

Brittany Williams
M.A., University of Louisville, 2013

A Thesis Approved on

April 11, 2013

By the following Thesis Committee

Karen Christopher, Committee Director

Mary Z. Ashlock

Nancy M. Theriot 


\section{ACKNOWLEDGMENTS}

I would like to thank my committee chair and advisor, Dr. Karen Christopher, for her guidance, patience and knowledge. I would also like to thank my committee members, Dr. Nancy Theriot and Dr. Mary Ashlock. I would also like to thank my Mother, Jennifer Sinski, for her support and encouragement throughout the process. 


\begin{abstract}
“THIS IS NOT WHAT MOTHERHOOD LOOKS LIKE": MOTHERS'

INTERPRETATIONS OF CULTURAL REPRESENTATIONS OF THE CELEBRITY

PREGNANT AND POST-PARTUM BODY

Brittany M. Williams
\end{abstract}

April 18, 2013

This research utilizes a feminist critical perspective to examine celebrity mom body (CMB) narratives in popular magazines and explore how they affect non-celebrity mother's body image based on class, race, and education. Face-to-face in-depth interviews were done with 25 non-celebrity women between the ages of 19 and 50 who have had one or more children to explore women's experiences in light of CMB Narratives. Women were asked questions about their bodies and experiences during and after pregnancy as well as shown images of pregnant and post-partum celebrity mothers from People Magazine, Us Weekly, Elle, and other popular magazines Despite the differences in levels of consumption, all women believed CMB narratives were problematic for women, as they normalized images of motherhood that were unrealistic for non-celebrity women. Further, this research found problematic differences in women's experiences based on their class, race, and education. 


\section{TABLE OF CONTENTS}

PAGE

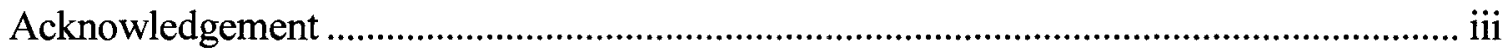

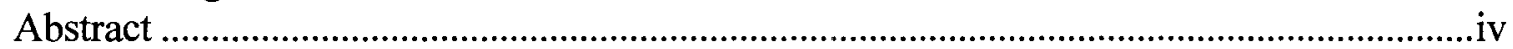

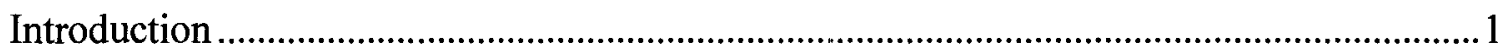

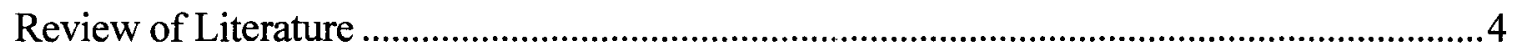

The Social Construction of Motherhood........................................................................

The Maternal Body ……............................................................................................

The Trend of Celebrity Motherhood ..........................................................................

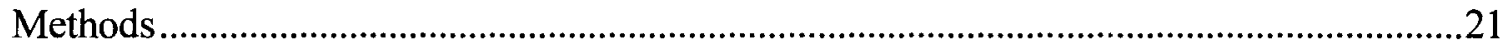

Table 1 Mothers' Race, Family Income, and Post-Partum Weight-loss Struggle..........24

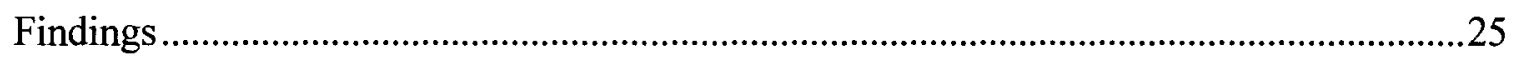

Mother's General Feelings on the Influence of CMB Narratives ....................................25

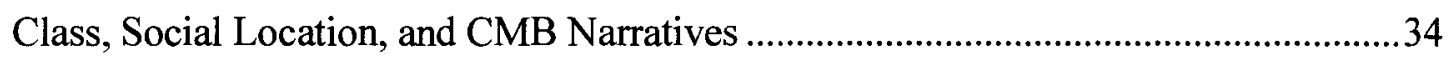

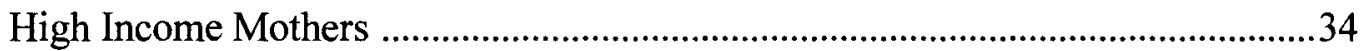

Low Income Mothers .........................................................................................

Racial Difference and the Good Mother ..........................................................................46

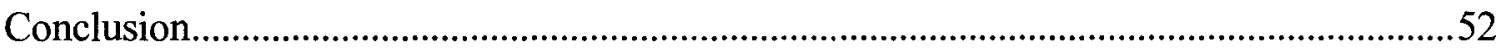

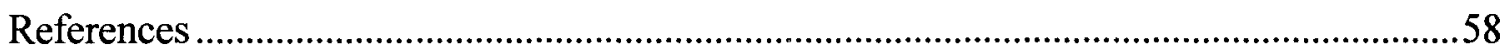

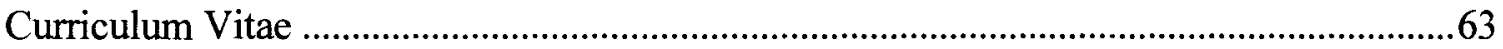




\section{INTRODUCTION}

Prior to the 1990's, a woman's pregnant body was considered private; mothers often hid their nude pregnant bodies from public consumption. However, this changed in 1991 when Annie Leibovitz photographed a pregnant Demi Moore nude for the cover of Vanity Fair, though it is doubtful Leibovitz could foresee the trend she started. Moore's posing nude with her second child was very controversial at the time; many stores insisted on selling the magazine closed in a package, while others refused to carry the 1991 issue at all. Despite its controversy, the 1991 issue became the bestselling single issue in Vanity Fair's history (Cunningham, 4). The focus of the camera is not on Moore's face. Instead, Moore gazes over her left shoulder, one hand curved and protecting her very visible seven-month pregnant belly, and the other hand covering her breasts. She is thin everywhere but her stomach, and is tan, glistening, and wearing large diamonds. Moore's' pregnant body becomes the subject for the public to monitor and scrutinize. This sparked a trend in which popular magazines shifted their coverage of mothers to focus on celebrity mothers' pregnancies, post-partum weight loss, and parenting styles. After Moore's Vanity Fair cover, popular magazines began regularly publicizing celebrity pregnancies as sexy and depicting postpartum weight loss as easy (Collins, 1991).

Into the 2010 s, celebrity pregnancies and workout routines are not only featured on magazine covers, but also on blogs, and in books and news headlines. The bodies of celebrity mothers thus became ideal types of pregnant and postpartum bodies. The focus 
on celebrity motherhood starts with tabloids obsessing over celebrity "baby bumps," followed by sensational headlines quickly shaming them back into their skinny jeans. Arguably, these fantasy driven narratives overshadow the realities of everyday women and their struggles with body image. Media portrayals of celebrity motherhood include neither women's diverse experiences of pregnancy nor women's varying experiences with their post-partum bodies.

This research utilizes a feminist critical perspective to uncover how media featuring celebrity pregnancies and postpartum bodies can affect non-celebrity mothers. This research examines celebrity mom body (CMB) narratives in popular magazines and explores if and to what extent they affect non-celebrity women's body image. It also asks how these processes are mediated by social class. In short, this research analyzes how mothers discuss their bodies in light of $\mathrm{CMB}$ narratives and examines the effects of class, race, and education on mothers' reactions to $\mathrm{CMB}$ narratives.

Very little empirical research has explored how non-celebrity women from different socio-economic and racial backgrounds experience their pregnant and postpartum bodies in light of CMB narratives. I explore how often non-celebrity women consume CMB narratives and how they feel about their own bodies after viewing them. My research offers a new lens through which to critically view motherhood experiences in a culture obsessed with celebrity motherhood. First, this research examines how women view their bodies in the face of unrealistic expectations portrayed in $\mathrm{CMB}$ narratives. Further, it analyzes mothers' responses to CMB narratives as they intersect 
with mothers' race and class backgrounds. Unlike existing research on celebrity motherhood, this research critically considers the lived experiences of mothers and the effects of CMB narratives on their identities. 


\section{REVIEW OF THE LITERATURE}

\section{The Social Construction of Motherhood}

Research on motherhood suggests there are many different maternal experiences and expectations for women. Dominant cultural ideals define what it means to be a good mother, how motherhood should shape women's identities, and what behaviors are deemed appropriate for mothers. Images of motherhood reflect social and traditional attitudes of true womanhood, which characterizes women as nurturing, passive, domestic, and self-sacrificing (Friedan, 1983; Johnston \& Swanson, 2003). In the 1960's, Betty Friedan's The Feminine Mystique explored problematic tensions between predominant social constructions of motherhood and the actual lived experience of women in society. Friedan refers to idealized images of women as the feminine mystique, which has been socially constructed by men as the 1950 's June Cleaver suburban housewife who is a conformist, stiflingly domestic, and enthusiastically fulfilled. The Feminine Mystique situates women within the private sphere, where they are dutiful homemakers completely fulfilled by their motherhood roles. While this narrative has been challenged in recent decades, it continues to influence our current expectations for women.

Many feminists propose that Friedan's social construction of motherhood creates a "motherhood mask" in which women strive to conform to unrealistic images of motherhood (Rich, 1976; Friedan, 1983; Maushart, 1999). In her book, Of Woman Born, Adrienne Rich suggests that discourses surrounding motherhood developed under 
patriarchal dominance, which resulted in loss of women's reproductive control, constricted roles for women, and a masked reality for motherhood. Within this "masked reality," mothers are expected to be all-knowing and spend all of their time, energy, and money on their children. Rich believes that mothers can only be empowered if they could have an open dialogue on the difficulties of motherhood. Additionally, Rich advocates larger institutional changes_-beginning with policies affecting mothers and media representations of motherhood.

Susan Maushart (1999) studied the new generation of mothers in the 1990s, and applied Rich's (1976) mask of motherhood to modern day women. Maushart suggests modern women face similar pressures as those studied by Friedan and Rich, but within a different context -- a more complex, competitive version of motherhood in which mothers are expected to be selfless caregivers and maintain successful careers and lives outside of the domestic sphere. She argues that, "our deeply confused notions about motherhood are engendering a tidal wave of guilt, resentment, and anxiety among today's women" (xx). Building upon Rich's mask of motherhood, Maushart argues that because women are likely unable to meet society's expectations of the selflessly fulfilled June Cleaver stereotype, women are now faced with intense feelings of guilt and shame that are typically borne in silence. She defines the mask of motherhood as socially constructed representations that present motherhood as "mostly brave, serene, and all knowing - that we use to disguise that chaos and complexity of our lived experience" (2). Here Maushart extends prior research on motherhood by applying it to the struggles experienced by contemporary women. However, she does not explore how women view their own bodies and the role that media images play in structuring such views. 
Recent feminist research supports the idea that the social construction of motherhood can be damaging to women's identities (Meyers, 2001; Collett, 2005; Miller; 2005). In Making Sense of Motherhood: A Narrative Approach, Miller (2005) argues that women should not perceive motherhood as a universal experience, because all women's experiences of motherhood are different. She conducted field research on women's experiences of being a mother and how motherhood changed their lives. Miller concludes that the mask of motherhood often gives women few things to feel good about, suggesting this "mask" does a major disservice to women by propagating images of the forever fulfilled mother who loves every minute of birthing and parenting.

Feminist theorists argue that women currently face the same socially constructed images as women in the 1950's "cult of domesticity," only in forms of popular media depictions of motherhood (Hays, 1996; Meyers, 2001). Hays (1996) describes opposing images of the dutiful homemaker and the supermom who juggle career and parenting. These images of motherhood create an artificial divide between stay-at-home mothers and career mothers over which is valued more in society. The socially constructed image of the traditional stay-at-home mother is one who dedicates all of her energy and happiness to her children. The opposing image is that of the supermom, who successfully juggles her career and home life. Hays argues that within thee ideologies the supermom believes the stay-at-home mothers are lazy, while stay-at-home mothers believe the supermom neglects her children. Further, Hays states that these depictions of motherhood are problematic, because they overemphasize and perhaps even create divisions between working and stay-at-home mothers. 
In addition to the lingering influence of The Feminine Mystique, mothers today must face the perfect mother in the form of Celebrity Mom Body (CMB) narratives, the media depictions of celebrity mothers' pregnant and post-partum bodies. Many feminists (Hopper, Aubrey, 2011; Cunningham, 2002) claimed the obsession with celebrity motherhood began with Demi Moore's Vanity Fair cover in 1991. The 1991 issue became the bestselling single issue in Vanity Fair's history (Cunningham, 4). Moore's cover sparked a trend of objectification and commodification of the pregnant female body, providing the maternal image for public consumption and pleasure. Many celebrity women emulated Moore, going on to pose nude or draped in jewels while pregnant. Thus, pregnancy photos became a lucrative and successful celebrity business.

Overall, the literature reviewed above suggests that the social construction of motherhood has negative effects on women's identities and personal autonomy. The guilt and shame associated with the inability to match real experience with the aforementioned socially constructed forms of motherhood perpetuates a cycle of silence among women who therefore do not share their real experiences of motherhood with other women. As a society, we ignore the less appealing narratives of pregnancies-the ones with swollen ankles, or sagging breasts from breast-feeding.

\section{The Maternal Body}

Feminist theorists explore how expectations for mothers changed as motherhood moved from a private matter to a cultural obsession. Historically, fertility and medical discourse remained hidden and privatized for fear of shame, but eventually evolved into a media spectacle (Thurer, 1994; McMahon, 1995; Balsamo, 1996; Chambers, 2009). Previously, birthing and mothering remained restricted to the private sphere-to be 
shared only with other women. Midwives supervised women's medical needs and the birthing process from the patients' homes. The technologies and advancement of birthing and motherhood has progressed since $19^{\text {th }}$ century private birthing experiences, and developed into a public display of the act of being pregnant. Many feminists claim that women lost agency over their bodies the minute male physicians stepped into the birthing room in the early $20^{\text {th }}$ century. Male physicians advocated modern science and medicine over midwifery and women's knowledge. The shift of birthing practices to hospitals in the early $20^{\text {th }}$ century allowed for an increased surveillance of reproduction as part of an institutionalized practice of "new science" which allowed physicians to have the control over the pregnant woman and the conditions to be set by institutions. For example, in the article Public Pregnancies and Cultural Narratives of Surveillance, Anne Balsamo uncovers a discourse of maternal surveillance that emerged in the 1990's during a time of media obsession with public and problem pregnancies. The maternal surveillance of women's bodies by society creates a new identity for the female body, one in which it is "evaluated in terms of its physiological and moral status as a potential container for the embryo or fetus" (Balsamo, 90).

Popular media serves as another avenue for maternal surveillance of women's bodies. Media images of women provide graphic representations of the ideal form of motherhood; mothers then compare their own bodies to these images and often view themselves unfavorably (Gardner et al, 1980; Martindale, 2012). Feminist theorists have observed a cultural obsession with media images, most of which pressure women to conform to unrealistic body types and thus exert control over women's bodies (Fredrickson, Roberts, 1997; Narayan, 1997). Theorists suggest that a cultural ideal of 
thinness has created unattainable standards for the vast majority of women in society (Gardner et al., 1980; Wolf, 1991; Bordo, 1993). The cultural obsession with thinness also affects pregnant women, who deal with major body changes during their pregnancy (Gardner, 1980; Bordo, 1993; Collett, 2005). Now pregnant women experience an added pressure to remain thin and contained during their pregnancy. For example, in the book Unbearable Weight, Bordo describes femininity as the ability to remain thin and contained, requiring "the female hunger-for public power, for independence, for sexual gratification—be contained" (171). She argues that society expects a tight, toned, and contained body type that portrays the traits of self-control and passiveness as female beauty. Bordo suggests that tightness for the female body means a physically toned body with no visible bulges.

Society celebrates the tight masculine body images of control and success. Weight then becomes a graphic representation of the physical and emotional health of women in society. Bordo goes on to say that societal standards of female indulgence originated in Victorian codes of conduct that warned of the dangers involved with overeating. Additionally, these codes dictated how women should eat and carry themselves in a watchful, controlled manner that is more feminine. Today popular media and consumer culture polices feminine behavior. Parodies and comedies portray large women with insatiable appetites; meanwhile famous celebrities model thin and contained bodies in advertisements and magazine articles. Slenderness remains the contemporary ideal of female attractiveness, even while capitalism encourages mass consumption almost to the point of excess. Bordo maintains that consumer culture bombards people with temptation and excess but society condemns them for overindulgence. She theorizes that media 
images have considerable influence over women's thought processes and thus exert control over women's bodies. To maintain a feminine beautiful body while pregnant means keeping every other part of the body small and contained with exception of the pregnant belly (Bordo, 1993; Gentile, 46; Cunningham, 2002; Nash, 2005).

Research has shown that after having children, the majority of women's bodies do not return to their original form (Gardner, 1980; Cunningham, 2002; Jenkin \& Tiggeman, 1997; Johnson \& Williamson, 2004). After childbirth, most women do not immediately return to their pre-pregnancy size or weight, and many women never regain their prepregnancy shape. Additionally, research in postpartum weight loss shows that many women experience feelings of grief and disappointment in regards to their body after pregnancy (Jenkin \& Tiggemann 1997; Johnson \& Williamson, 2004).

In Body Image Change in Pregnancy: A Comparison of Normal Weight and Overweight Primigravidas, Fox and Yamagushi (1997) research body image during pregnancy by examining the relationship between pre-pregnancy body weight and body image change in 76 women who were pregnant for the first time. Among normal-weight women, feelings of self-consciousness were common, and this was frequently attributed to a belief that they suffered an increase in public scrutiny. After their pregnancy, Collett (2005) says women might constantly remind people or inform them they just had a baby, so as not to confuse her changed body with one of laziness or "letting go."

\section{The Trend of Celebrity Motherhood}

Cunningham (2002) argues that an obsession with celebrity motherhood originated in Hollywood in the 1990s, during which time many actresses and super models began publicizing their pregnancies. A celebrity woman who successfully gets 
her body back is venerated and praised within the media. Not only were celebrity women reclaiming their pre-pregnancy bodies, but also their self-respect and careers. Celebrity mothers reappeared as their former toned and successful hard-bodied self, ready to take career by the reigns. They became "women to be emulated, admired, and envied," women who had successfully achieved the "prodigal body" (Cunningham, 2).

Current research on celebrity motherhood and body theory focuses largely on media depictions of celebrity mothers. Celebrity motherhood has largely been analyzed as a cultural trend that perpetuates unrealistic images of women. More recently, feminist researchers have extended feminist theory by analyzing media portrayals of celebrity motherhood. Much of this research uses content analysis of popular media to argue that the trend toward celebrity motherhood in the 1990s could have direct consequences for society (Douglas \& Michaels, 2004; Nash, 2005; Echeveste, 2008; Chambers, 2009; Pincus, 2010; Gentil, 2011).

The most influential contributor in celebrity motherhood research is Douglas and Michaels's 2004 book, The Mommy Myth: The Idealization of Motherhood and How It Has Undermined Women. The book takes a humorous approach to the capitalism of celebrity motherhood, opening with a story of an American checking out at the grocery observing magazines with celebrity moms exalting their nude pregnant bodies while "you . . f feel as sexy as Rush Limbaugh in a thong" (Douglas \& Michaels, 1). They suggest the portrayals of Hollywood elite mothers have become a cultural obsession, one that can lead to mother-shaming. Further, Douglas and Michaels critique the role of the mass media in "promulgating and exaggerating" myths about motherhood, arguing that the mass media's representation of motherhood has created an environment of hyper- 
competition, guilt and anxiety for women. They argue that celebrity motherhood resurrects traditional portraits of women who are, "nurturing and maternal, love all children, and prefer motherhood to anything...More perniciously, they exemplify what motherhood has become in our intensified consumer culture: a competition. They rekindle habits of mind pitting women against women that the women's movement sought to end, leaving the notion of sisterhood in the dust" (Douglas \& Michaels, 138). Motherhood has become a competition as mothers try to out-perform other women in parenting, weight loss, and overall dedication to motherhood. Christie Brinkley, in a Redbook interview admits that she is a very competitive mother, "I just want to push myself to be the best I can be. I want to be a good mother to Alexa and Jack" (Redbook, 1997).

More recent research on celebrity motherhood shows the trend of Hollywood moms in the media beginning in the 1990s (Gentile, 2011; Echeveste, 2008; Chambers, 2009; Hopper \& Aubrey 2011; Oliver, 2010). Gentile (2011) argues that the obsession with pregnant celebrities intensified with the covers of 1990s magazines. In Motherhood, Sexuality, and Pregnant Embodiment: Twenty-Five Years of Gestation, Oliver (2010) analyzes the eroticization of the pregnant body in popular culture. Specifically, Oliver examines the trend Demi Moore started in 1991. Moore's body represented an entirely novel form of sexualizing women's bodies. Oliver argues that this perpetuates a longstanding tradition of sexualizing women's bodies in popular media. "Their bodies and their desires are imagined for others, for men, for the viewing audience, and not for themselves or as women themselves experience their own sexuality or desires" (765). Much of Oliver's analysis focuses more on Hollywood films rather than print 
publications following the Vanity Fair cover featuring Moore. Tyler (2001) also analyzes the trend that Moore started, claiming that until Moore posed nude while pregnant, the pregnant body had been absent from media representation and other visuals. Tyler provides a closer reading on the photograph of Moore's portrayal as both maternal and erotic, substantiating Oliver's claim of the increased sexualization of women's bodies in popular media.

No mother, regardless of class, is immune from societal pressures, childcare expertise, and other intensive mothering ideologies that stress the model of stay at home mother, fully committed to pleasing her child. Feminists adopting intersectional analyses have argued that race and class intersect with gender to create more stringent standards for mothers of color. For example, low income and/or mothers of color are often held to higher standards than higher income or white women; the former can only focus on their children, or society shames them. Specifically, Roberts (1997) looks at recent legislation and societal efforts to control black women's bodies and advocates a woman's right to raise children without the white upper class criminalizing and scrutinizing every aspect. These mothers are "ideologically assaulted because of their premature and impoverished entrance into the realm of motherhood while older, whiter, and wealthier women are coaxed to buy the technology to assist them in achieving an utterly commodified motherhood" (Davis, 513) Thus, these women do not spend money or admit to any of this lifestyle, because to spend money on anything other than their children criminalizes them as a mother. In Black Feminist Thought, Patricia Hill Collins argues that, "institutions controlled by Whites clearly show a preference for lighter-skinned Blacks, discriminating against darker ones or against any African-Americans who appear to reject White images 
of beauty" (91). This is evident in CMB narratives that typically showcase flawlessly toned white celebrity mothers as the cultural norm. Although many celebrity women of color have achieved popularity and mass media representations, it has been argued that popular celebrity women of color have been "whitewashed" and "anglicized" due to their extreme weight loss, makeup, and straight hair, (Guzman \& Valdivia, 2004).

This new cultural representation of pregnant embodiment stresses a body that can be disciplined into a skin-tight sexualized version of motherhood. Magazines and newspapers play a significant role in constructing meanings about which bodies and appearances are socially acceptable, desirable, right, or fashionable (Kaiser, 1997). A shift in popular culture regarding 1950's motherhood and women's bodies was 'fostered by the proliferation of women's magazines and advice books that together created a unified ideal of femininity that has been termed the cult of true womanhood or domesticity" (Gentile, 40). It seems that magazines in the 1990s served as reinforcements of the cult of domesticity that Gentile describes.

Many newspapers have picked up on this phenomenon of celebrity motherhood in magazines (Bernstein, 2012; Marikar, 2011; Martindale 2012; Min, 2012). Bernstein (2012) claims that motherhood pays because women flock to buy the magazines showcasing pregnancies. Quite often, celebrity moms sell their story along with a deal to sell pictures of their postpartum weight-loss plan as well. In a 1994 Redbook article titled, "Sela's Baby Jitters," actress Sela Ward is interviewed about her pregnancy. The article details Ward's pregnancy and the anxiety she has over gaining weight. Ward once used to be on a strict diet designed by a nutritionist, but now she "only craves Taco Bell." In contrast, actress Heather Locklear's pregnancy was written into her television role. She 
told readers that during her entire pregnancy she never ate anything unhealthy and only gained 22 pounds by, "eating only vegetables, fish and chicken" and "took daily walks and pumped light weights three or four days a week" (People, 1997). Thus, celebrity women appear to be in competition with each other to take up as little space as possible throughout their pregnancy. Ward admits to having cravings for fast food, while Locklear focused on a strict diet throughout her pregnancy. Their habits and cravings are put on display to be pitted against one another and judged for shortfalls.

Portrayals of celebrities glamorize motherhood and echo a culture obsessed with thin bodies that might be sending women the wrong message (Malkin et al., 1999; Douglas \& Michaels, 2004; McRobbie, 2006; O’Donohoe, 2008; Chambers, 2009; Morris, 2010). In her article, Oh Baby, Baby: (Un)Veiling Britney Spears' Pregnant Body, Meredith Nash explores the media obsession with Britney Spears' body-the transformation to the maternal form and then to the postpartum form. Nash reviews culturally problematic tensions in society surrounding pregnant embodiment, as the pregnant body directly challenges the construction of femininity as thin and contained. Similarly to Nash, other studies have been done on the objectification of pregnant bodies. In her article, The Flaunting of Fertility: Popular Media Representations of the Maternal, Deborah Chambers looks at the flaunting of the "ornamental bump" in media spectacle. Chambers' study, done in the UK, examines the ways popular culture uses fertility to inscribe meanings to women as subjects from 1990 s to 2009 . Chambers' focus is specifically on the sexualization and "grotesque feminine excess" of the celebrity pregnant body. Captured through the lens of a camera, the media is obsessed about the 
maternal form. Whether it be Britney Spears or the Octomom, maternal images are lucrative.

It has been argued that popular media perpetuates unrealistic standards of beauty and of weight (Wolf, 1991; Faludi, 1991; Bordo, 1993; Kilbourne, 1999; Frederickson \& Roberts, 1997). For example, in Women and Weight: Gendered Messages on Magazine Covers, Chrisler, Malkin, and Wornian (1999) do a content analysis on the covers of 21 popular women and men's magazines, looking for gendered messages in relation to body images. Some of the magazines included Vogue, Redbook, Glamour, and Gentlemen's Quarterly. Within this research, (although the results do show that women's magazines focus heavily on weight) pregnancy is not mentioned. Their findings showed that $78 \%$ of women's magazines had covers displaying messages related to physical appearance, while none of the men's magazines addressed these issues. Additionally, their research showed that $94 \%$ of women's magazines featured a thin female on their cover. Overall, they concluded that women's magazines were more likely to contain images and messages of diet, weight, and physical appearance.

Several content analyses have examined how media objectify both women and men, but there is limited research on the effects of media on pregnant women during and after their pregnancy. Aubrey and Hopper (2011), examined celebrity gossip magazines and the effect they had on pregnant women's self-objectification. They argue that most women view themselves through the lens of the observer, which causes women to consistently monitor their bodies and overall appearance in society. Over 300 pregnant women were shown a headshot of objectifying images of celebrity women and asked what they thought of the images, but no in-depth interviews were done to further explore 
respondents' reactions to the headshots shown. Their findings showed that exposure to such images objectified in the media did result in significantly more self-objectification. Women farther along in their pregnancy were more likely to compare their own bodies to these objectified full-body images of celebrities than women who were only in their first trimester.

Moving from the pregnant body, media quickly focuses on post-partum weight loss success among celebrity mothers. In, "Getting Your Body Back": Postindustrial Fit Motherhood in Shape Fit Pregnancy Magazine, Dworkin and Wachs (2004) conduct a content and textual analysis of Shape Fit Pregnancy magazine. Once the celebrity pregnant body has been announced or exposed on the cover or within the magazine, the next step is to monitor the postpartum body, otherwise known as "getting your body back" (Cunningham, 2002; Dworkin \& Wachs, 2004). "Letting the body go," has famously been used when discussing new mothers who did not immediately get their prepregnancy sexual body back (Dworkin \& Wachs, 616). Forget maternal duties, the emphasis is on the active mother who immediately begins working out and dieting to reclaim her pre-pregnancy body. Magazines feature before and after photos of women working hard to return to their "normal body." Women are bombarded with images of slenderness and containment immediately after pregnancy, a time when, "women feel overwhelmingly unattractive" (Dworkin \& Wachs, 612). A woman's body changes not only physically but hormonally, which can be hard for some women to accept.

McRobbie (2006) echoes Dworkin and Wachs' concern for postpartum weight loss pressures in "Yummy Mummies Leave a Bad Taste for Young Women." McRoobie also talks about the portrayal of celebrity mothers in the media who can successfully 
bounce back into shape after having their baby. She suggests that "the svelte figure of the high-income yummy mummy who can squeeze into size six jeans a couple weeks after giving birth, with the help of a personal trainer, has become a favorite front-cover image in the celebrity weeklies." Additionally, O'Donohoe (2008), claims that North American consumption of the "Yummy Mummy" has also started in the UK. Her research is written from a British perspective, but also draws on American celebrity images.

Additional examples of post-partum weight loss fixation on celebrity mothers can be seen in popular magazines of the 1990s. In 1992, Redbook magazine featured "Dropping Post-Pregnancy Pounds," which showcased celebrity mothers who had successfully lost all of their baby weight. However, celebrity insights make postpartum weight loss seem simple. People magazine was the first to label these trendy celebrity mothers as the new "hot mom." The May 1997 People cover proclaimed, "The New Sexy Moms!" with Niki Taylor shown walking on her knees carrying her twin on her backs as a "workout," while Pamela Anderson is shown laying with her newborn baby staring longingly at the camera. Inside the issue is the quote, "from regaining their sleek figures to nursing on the set between takes, Hollywood moms find ways to have it all" (People, 1997). A much smaller and toned Niki Taylor is seen laying in a bubble bath with her twins, her long legs kicked up in the air playfully. This article is different than most by including the amount of weight that Taylor gained during her pregnancy, "a whopping 70 pounds while eating for three." This article features Taylor as a fit mother who ran two miles up to seven months in her pregnancy but then suddenly "ballooned" to a size 20 . Although Taylor admits to gaining 70 pounds during her pregnancy, it does not include the efforts she took to reclaim her supermodel figure. Taylor also claims that her stretch 
marks "just disappeared after a while!" (People, 1997). If her successful modeling career and weight loss weren't enough to make mothers jealous, the stretch marks surely did them in. Later in 1998, Elle Macpherson told People, "she has already returned to prepregnancy form without any special attention to diet or exercise" (People, September 1998). In a Redbook article titled, "Dropping Post-Pregnancy Pounds," women are encouraged to return to work as quickly as possible because of a study done that showed women losing more weight by going back to work. Interestingly, the article also blames the women who did not drop weight, writing that the pregnancy was "probably not to blame" for their inability to lose weight (Redbook, 1992). In the case of this Redbook article, women's weight loss and success in the workplace go hand in hand.

Most recently, in 2012 the former Editor of Us Weekly Janice Min wrote a piece for The New York Times titled, "Can a Mom Get a Break?" in which she confronts mothers who do not return quickly to their pre-pregnancy figure. Min admits that she is partially responsible for a cultural addiction to celebrity mothers and suggests there are only two desirable body images in Western culture for mothers - the one with a cute little baby bump and one that goes immediately back into shape (sometimes even better shape than before the baby). Overall, research suggests that society judges images of celebrity mother's successful weight loss. Women who fail to lose their post-partum baby weight are often ridiculed in the media.

Very little empirical research explores the impact of $\mathrm{CMB}$ narratives on noncelebrity women's experiences, and this research fills this gap. While Aubrey and Hopper (2011) include women in their research, they focused on a content analysis rather than women's lived experiences. In contrast, my research explores how non-celebrity women 
feel about their own bodies when looking at CMB narratives. This research draws from the feminist theories reviewed above to explore non-celebrity women's voices and the differences in these voices by class, race, and education. The in-depth interviews provide an understanding of the many different experiences of non-celebrity mothers that can inform and broaden feminist research. Lastly, this research is important for changing existing discourses on motherhood and creating new constructions of what motherhood really looks like. It illuminates the problematic effects of CMB narratives on women's self-image and the possibility for a new identity for women instead of "getting their body back." 


\section{METHODS}

This study uses 25 in-depth interviews with non-celebrity women who have had one or more children. Interviews were done face-to-face to explore women's experiences in light of CMB Narratives. From January to March of 2013, I interviewed mothers between the ages of 19 and 45 , because these are the ages I believe consume CMB narratives most often.

This research uses a non-random, convenience sample of women in a moderatelysized Midwestern city. I recruited respondents for my interviews with flyers and social media advertisements targeting women of different socio-economic backgrounds. Some respondents were found utilizing snowball sampling, through which respondents provided me names of additional mothers who might be willing to participate in the study. Only five women in my research were found through snowball sampling. The interviews I conducted were done either in public places of respondents' choosing, or in the privacy of their own homes. These interviews were semi-structured, as each woman filled out a small set of demographic questions, and then I worked from an interview guide; however, I gave women substantial leeway to discuss the issues that were most important to them. I began by explaining to each woman what $\mathrm{CMB}$ narratives meant in regards to this research. Then I asked general questions on their media consumption and backgrounds. Following these questions, I showed each woman images of pregnant celebrities and then images of celebrity mothers' post-partum weight loss from People Magazine, Us Weekly, Elle, and other popular magazines. After the images were shown, 
women began to feel more comfortable; respondents often opened up and discussed more personal experiences with motherhood and their bodies.

Each interview lasted between 35 minutes to 75 minutes, but most were about 45 minutes. After each interview, respondents were assigned a number and pseudonym. All interviews were digitally recorded and transcribed.

As seen in Table 1, these mothers came from many different racial and socioeconomic backgrounds. I realized I needed to change some of my questions to directly address the lack of racial diversity in $\mathrm{CMB}$ narratives when the first African American woman I interviewed pulled me aside after our interview and expressed her concern over representations of black motherhood. In my notes I quoted her saying, "as a black mother...I have Beyonce and Jennifer Hudson to look up to in the media. Who else is there? Women like me don't sell magazines." That stuck with me-_"women like me do not sell magazines." Did she mean African American women did not sell magazines, or that African American mothers do not sell magazines? Based on her input, I asked all other women of color how their bodies changed during pregnancy, and if these changes were similar to women's bodies in CMB narratives. I believe this additional question allowed women of color to be more open about their experiences and how they might differ from $\mathrm{CMB}$ narratives.

Once my interviews were complete, I re-read transcripts several times and then coded each interview according to themes and patterns that emerged from all the interviews (Hesse-Biber \& Leavy, 2007). Once general themes were found, I coded interviews again for more specific themes related to race and class (Charmaz, 2006). As seen in Table 1, there were 15 white women, 7 African American women, 1 Asian 
woman, and 2 racially mixed women. Of those women, 11 were lower income, 3 lowermiddle income, 2 upper-middle income, and 9 were upper income. Lower income women earned under 20,000 annually; lower-middle income women earned between 20,001 and 45,000; upper-middle income women between 45,001 and 99,999; and high income women earned over 100,000 per year. This sample over-represents both low income and high income mothers, so the themes found here may be more relevant to these mothers (than to middle class mothers).

Lastly, while writing my findings and conclusion, I used two feminist theories as a frame for this research: feminist standpoint theory and intersectionality (Sprague, 2005). Using feminist standpoint theory, I take the standpoint of women in order to understand their unique experiences in light of the power exerted by CMB narratives over the women's pregnant and postpartum bodies. Semi-structured interviews allow women to discuss their lived experiences of social phenomena, such as consumption of popular media; as seen below, these women evaluated CMB narratives from their own points of view. Drawing from an intersectionality perspective (Collins, 1994 \& 2004; Roberts, 1997), and the literature above that looks at women's diverse experiences of motherhood, I also looked at how mother's experiences of CMB narratives intersected with their racial identity and class background. 
Table 1. Mothers' Race, Family Income, and Post-Partum Weight-loss Struggle

\begin{tabular}{|llll|}
\hline Names & Race/Ethnicity & Family Income* & Post-Partum Weight-loss Struggle \\
\hline Rebecca & White & Lower & No \\
\hline Paige & African American & Lower & No \\
\hline Susan & White & Lower & Yes \\
\hline Carrie & White & Lower & Yes \\
\hline Ashley & African American & Lower & Yes \\
\hline Erica & White & Lower & Yes \\
\hline Leah & African American & Lower & Yes \\
\hline Candace & African American & Lower & Yes \\
\hline Melissa & African American & Lower & Yes \\
\hline Kimberly & African American & Lower & Yes \\
\hline Shauna & White & Lower & Yes \\
\hline lessica & Asian & LM & Yes \\
\hline Tracy & White/Lebanese & LM & Yes \\
\hline Eva & White & LM & Yes \\
\hline Kelly & Black/Asian & UM & No \\
\hline Samantha & White & UM & Yes \\
\hline Jennifer & White & Upper & No \\
\hline Angela & White & Upper & No \\
\hline Tiffany & White & Upper & No \\
\hline Anne & White & Upper & No \\
\hline Caroline & White & Upper & No \\
\hline Marie & White & Upper & Yes \\
\hline Miranda & White & Upper & Yes \\
\hline Brooke & White & Upper & Yes \\
\hline Alison & White & Upper & Yes \\
\hline & & - & \\
\hline
\end{tabular}

*The category of family income is based on the average US household income of $\$ 50,502$. Lower income women earned under 20,000 , lower-middle income women earned between 20,001 and 45,000; upper-middle income women between 45,001 and 99,999 , and high income women earned over 1000,000 per year. 


\section{FINDINGS}

\section{Mothers' General Feelings on the influence of CMB Narratives}

I interviewed 25 mothers from different socio-economic backgrounds about their $\mathrm{CMB}$ consumption habits and views on their bodies in light of motherhood narratives in the media. As shown in Table 1, women ranged from ages 19 to 45 , with the average age of 31 . These women had 1 to 4 children, consumed between 1 and 8 hours of popular media, but on average their daily media consumption consisted of 3.4 hours. Their media consumption derived from popular magazines, TV, online news sources, and smart phone apps. Out of these 25 women, only 10 women openly admitted to actively seeking CMB narratives in the media. The women that candidly spoke with me about their "guilty magazine pleasure" or "trashy magazine habits," were not ashamed that they subscribed to popular magazines such as People, Us Weekly, Cosmo, or Shape. Tiffany explained that, "it is a total escapism from my tedious day to day tasks. Sometimes it is refreshing to look at pretty people instead of grading papers." Another mother, Eva, who is currently finishing her Master's degree admitted that, "I read these when I am having my me time, like taking a bath or getting my hair done. It's nice to get away for a little bit." Some women picked their grocery checkout line according to which one had with best magazine headlines.

Nonetheless, the majority of the mothers interviewed were more hesitant to admit their consumption, indicating an ambivalence and denial in regards to their consumption of CMB narratives. When asked if they ever bought magazines such as People, Us 
Weekly, Ok! Magazine, or Shape while waiting in line at the grocery store, 15 of the mothers quickly denied such purchases. Caroline explained to me that she only shopped at Whole Foods, which does not sell "low-class magazines" such as the ones mentioned above. Others claimed they had no time to follow CMB narratives. However, later in the interview, each of these women specifically mentioned stories from magazines, named celebrity mothers, or described advice they took from particular CMB narratives. These women associated a stigma to this kind of "guilty pleasure" entertainment and did not want to be viewed as the women with time to read these magazines. I asked one mother why she believed other women did not admit to reading or consuming CMB narratives, and she explained that she believed some women were afraid to admit their guilty pleasure in an attempt to portray themselves as better than or not affected by CMB narratives; but she said, "it infiltrates even the healthy living magazines. Even in Body and Soul, there will be a celebrity mother talking about vegan diets for a better way of living."

By the end of these interviews, the women had confessed to being a headline consumer of these magazines but not buying them-or realizing that subconsciously they had consumed more $\mathrm{CMB}$ narratives than they themselves had realized. For example, Paige explained to me very seriously that she did not buy into CMB narratives and had no time to follow their stories in the media. However, by the end of the interview, she had mentioned 11 celebrity mothers and their pregnancy or post-partum weight loss stories; she declared embarrassingly, "I know so much more than I thought I did!" Another woman explained that even though she did not actively seek out CMB narratives, so many of her friends followed and posted Facebook stories about Kardashians, Angelina 
Jolie, Snooki, and other famous mothers, that she was "aware of it through other people promoting it." One mother, Kelly, educated me on a whole other realm of CMB advertising. She recently had her third child and used pregnancy applications on her smartphone; she said, "there were celebrity mother advertisements popping up every other minute! I am a personal trainer and know what is best for my body, but I found myself clicking on them anyway to see what this new post-partum diet secret was!"

Based on media outlets these women mentioned, CMB narratives target women on morning news shows such as Good Morning America, on the radio while driving your kids to school, in magazines, on smartphone apps, and even in highly regarded newspapers. Whether women are actively following CMB narratives, or scrolling through a friend's mini-feed on Facebook, they are consuming these narratives, even if they are not seeking them out. Despite what their individual consumption level may be, each woman strongly believed CMB narratives were problematic for non-celebrity women and had negative effects on their self-esteem.

Many of the more highly educated mothers believed CMB narratives had been normalized in popular culture and stood as the defining form of motherhood and postpartum beauty. Carrie, a PhD student, explained, "since these narratives are so pervasive, it sets up this expectation that this is normal and you are not. That is such a difficult narrative to follow. I think a lot of women struggle with what they know is realistically attainable and the expectations they put on themselves because of these images. Women are so self-critical to begin with. They have this narrative in their head that this is what they are supposed to look like." Another mother echoed this sentiment, "these images are so normalized, that even someone like me who is aware and educated begins to compare 
themselves. We begin to think that we aren't normal, or less than because of the images we are surrounded by. That is so unhealthy." I asked Jennifer, a college professor and mother of two why she believed CMB narratives were so problematic for women, and she explained that, "the problem is that women are not willing to share their secrets...their diets, their plastic surgery. So we see celebrity women who look perfect, but most women don't stop to think about the extent to which these women have gone to look this way. As women, we hold ourselves to unrealistic standards and we want people to think we have somehow achieved this great body through hard work. I think you can really hurt your body and self-esteem to expect unrealistic things like this. Why not be realistic and talk to each other about how hard it really is?" Both Carrie and Jennifer echoed a common theme in these interviews—a lack of women's solidarity around opposing the normalized images consistently portrayed in CMB narratives. For example, a more open dialogue among women (including celebrity women) addressing bodily changes during pregnancy and post-partum weight loss struggle could serve to build this kind of solidarity.

Older mothers responded with more of a concern for younger generations who might be looking to get pregnant. For example, Kimberly said, "a lot of young girls are looking at these celebrities as role models, and oh we had our kid on the same day...but I am still huge and they are so tiny. That's where depression and eating disorders come about. A lot of young women follow celebrities and try to mimic them. That can be dangerous." Similarly, another mother said she was concerned for her daughters growing up: "I think it is problematic for average women, especially mothers and women who are waiting to have children-it alters their perspective of what being a mother looks like. 
This is not what motherhood looks like for the majority of America. It is hard, sometimes depressing, and full of imperfections." The future generations of young mothers were of main concern for these women, because women believed these younger mothers had no realistic role models in media.

Although many of the women said they did not believe celebrity women gave good advice, or that they were aware that these images were stylized and airbrushed, they still admitted at some point in their interview to taking advice from or comparing themselves to celebrity women during and after their pregnancies. All women were shown images of celebrity pregnant women showcasing their baby bump, followed by images of post-partum weight-loss.

Mothers were more likely to identify with the pregnant images of celebrities. It seemed that for many of the women, pregnancy became an equalizer-a shared experience women could more easily identify with. Even if women were not happy with their bodies while pregnant, it seemed that they were still likely to compare themselves to women in regards to weight because they had an "excuse" to be big. Samantha, a mother of two clarified, "I was okay with my body when I was pregnant. When you are not pregnant and you have the belly, it is much more shameful than when you are pregnant, because it is supposed to be there. Your stomach is firm and all one shape... as opposed to now when it is lumpy and bumpy. I have more trouble with it now, because I feel like it is not supposed to be there." Carrie echoed this feeling, "I thought it was very empowering to be pregnant, it was a fascinating time where my body never looked that way again. A lot of emphasis was put on being proud of your body and being amazed at what it was doing. So I enjoy that it isn't being hidden anymore-- that pregnancies can be 
public and beautiful." Pregnancy was a time most women could be comfortable with their bodily changes, and share a more unified experience with other mothers.

Women acknowledged that pregnant images of celebrities were airbrushed and stylized to make women beautiful. None of the women interviewed had photographs taken of themselves nude while pregnant-claiming they were not comfortable enough with their body at the time, or did not feel like it was appropriate due to personal or religious reasons. Some mothers praised celebrity images for showing the beauty of pregnancies, while others claimed it was disgusting to sexualize pregnancies. The biggest concern among mothers when shown images of celebrities pregnant bodies was the amount of airbrushing in $\mathrm{CMB}$ narratives. Otherwise, for the most part, women noted that celebrity pregnant women were beautiful.

However, mothers did admit to comparing themselves unfavorably to CMB narratives after their pregnancy. As seen in Table 1, 17 out of 25 women struggled with post-partum weight loss after the birth of their children. Of the 8 women who did not struggle post-partum, they still noted several aspects of their body they were not happy with after their pregnancy. Many women noted feeling defeated and pressured in regards to post-partum weight loss; Jessica said, "I just do not think it is possible. For pregnant celebrities, this is their job to look nice, so they work at this perfect body all the time, versus real women who have jobs, school, and other things to worry about. I can't always focus on eating better, getting up early to prep my meals and go for a 3 mile run." Samantha became very emotional when discussing her post-partum weight loss struggles: "I felt really defeated and often depressed in regards to post-partum weight loss. Pregnancy changes your body in ways you never imagined. My shoe size changed 
permanently, my body shape is different, and my hair is curly now. I think society and the media tells you that you get pregnant, have the baby and everything just goes back to normal." Many of the women reiterated to me again and again how problematic they believed $\mathrm{CMB}$ narratives were for women. For example, Tracy said "being pregnant and raising your child is an emotional roller-coaster, and everything is changing-hormones, your body. It is a hard adjustment. Every woman gains weight during their pregnancy, that is only natural. And then society tells you that you immediately have to drop it. Boom, it just shouldn't be there anymore. Then seeing these magazines in the grocery, showing celebrity women with flat stomachs four weeks after their pregnancy, it is impossible for women! I know it was hard for me. Still to this day, I struggle." Ultimately, all of these women admitted to facing unanticipated expectations for their bodies at some point after their pregnancies.

Not only did the mothers compare themselves to celebrity mothers, but the men in their lives also held their bodies to similar standards. All 25 mothers who participated in my in-depth interviews on celebrity motherhood said the men in their lives subscribed to what I began to call the "male myth"-- the assumption that women's bodies spontaneously go back to their pre-pregnancy shape following the birth of their child.

Many of the mothers admitted that the negative body image they had of themselves had a lot to do with how their partner viewed their body. Whether their husband or ex-partner called them fat or simply encouraged them to work out, these women internalized their partners' negative comments. Melissa, a mother of two who struggled with her weight while caring for her ill parent claimed, "men think all women should look like these celebrity mothers. I think some are okay with the baby weight, but 
most want you to drop it immediately. The father of my children did. He didn't want to be around me because I was so big. He told me I was so fat all the time. The doctor would explain to him I was retaining water." Although she had a medical reason for her weight gain, she associates his negative image of her body during pregnancy with their relationship ending. Another mother also associated her relationship problems with a negative body image during pregnancy. "Since I've been pregnant, he doesn't show me attention. This happened during my other pregnancies as well...but I keep putting up with it. Women have a lot on their shoulders right now trying to be superwoman. Trying to work, go to school, take care of children, their husbands, clean the house-while men sit there and do what? Come home and just be lazy because they make all the money? It isn't fair." Some women claimed their husbands' criticisms were healthy criticisms to keep them motivated. Miranda said, "my husband would tell me to go work out, because he knew it would make me feel better about myself. But also...I mean he probably wanted to see the benefits of it." Similarly, Kelly, a personal trainer and mother of two admitted her husband quickly encouraged her to get back into the gym so she could "be happy with herself again." Overall, these women's comments suggest that men did not understand or appreciate the significant changes in women's bodies or the pregnancy process.

Some of the women interviewed even claimed that men were disgusted by the pregnancy process. Kimberly, a mother of three, whose husband left her for another woman during her last pregnancy, explained that, "some men have complete aversions to pregnancy and weight gain. My ex-husband did not like it. He was like EW! I would do little belly dances to tease him and he would be disgusted." Another mother explained 
men's aversion to pregnancy in more depth: "I think men in general are freaked out by pregnant women. Women's bodies have been so sexualized...I think when the body changes, it just totally freaks them out. I think some men, once a woman has a babythey never see their partner outside of their maternal role again. The sex is never the same. I think it is hard for men to separate your role as a mother and your role as a woman. I think men are harder on women about their weight also." A sign language interpreter bouncing her toddler on her knee claimed, "my partner doesn't pay any attention to these and probably wouldn't even be able to name them. But I think most men believe in these myths-that our bodies can just bounce back. But men don't get a lot of things, especially pregnancy." Each mother interviewed experienced pregnancy with their partners differently. Some women claimed their husbands were happy or even excited about the changes in their bodies during pregnancy. Tiffany explained that her husband enjoyed seeing her body change during their first child, saying, "he was always supportive and would encourage me that I was beautiful." Clearly while some men were very comfortable and happy with their partners' pregnant bodies, others were impartial or even repulsed.

Despite the experiences with their partners, all 25 women interviewed said that men in general assumed all women's bodies could resemble those of celebrities in CMB narratives immediately after pregnancy. Specifically, men believed the myth perpetuated by the media: the female body bounces back very quickly after pregnancy. Jennifer, a psychology professor, believed "most men are under the impression that after the baby, you just go back to your normal weight. If these women did, you can too. Eat healthy, work out, it is easy right? Most don't realize that many of the changes with our bodies are 
permanent." Research has shown that after having children, the majority of women's bodies do not return to their original form (Gardner, 1980; Cunningham, 2002; Jenkin \& Tiggeman, 1997; Johnson \& Williamson, 2004). Along with weight gain, women also experience changes in the shape of their hips, feet, and texture of their hair. Additionally, research in postpartum weight loss indicates that many women experience feelings of grief and disappointment in regards to their body after pregnancy (Jenkin \& Tiggemann 1997; Johnson \& Williamson, 2004). The first mother I interviewed suggested the social construction of motherhood was a huge problem for men and women because, "when the only other pregnant bodies you have seen is this-you have no realistic comparison. So when your partner is pregnant—she becomes the minority while these are the majority. Even my daughter would think this is the norm." Many of the 25 mothers interviewed for this study believed there was an absence of networking and communication among women in sharing the imperfections and reality of pregnancy and motherhood. Overall, despite the many differences between the mothers I interviewed, there was agreement about the negative effects of $\mathrm{CMB}$ narratives on non-celebrity women and their husbands.

\section{Class, Social Location, and CMB Narratives}

\section{High Income Mothers}

Of the women interviewed, 10 were high-income mothers. As seen in Table 1, all of these women were white. Most of these women came from similar traditional backgrounds of middle and upper class families whose fathers were breadwinners and mothers stayed home to care for the children. These women were married to influential men in the community, or successful business owners. However, two of these mothers 
were $\mathrm{PhD}$ educated college professors who were married to men within their field. All 10 women graduated from college and did not have children until their early thirties. Opportunities were abundant for these women to say the least; they had far more social and economic resources than the low income mothers, whose narratives are discussed below.

Although many of these women had complained at some point in the interviews about their bodies, all but two believed you could have post-partum success if you were fit before your pregnancy. However, all of these women come from a place of wealth and privilege-having one or more gym memberships. Specifically, a personal trainer named Angela was very critical of other mothers who were not physically fit after pregnancy, "I do not think women should use pregnancy as a crutch, like oh, I had 2 children. No, you just don't work out or you don't work hard enough. If you had a flat stomach before kids, you can again. If you didn't before, then no it is not going to happen." Another mother, Anne, believed post-partum success had a lot to do with how fit you were before pregnancy, and with good genes. On the contrary, Brooke, a very sarcastic mother who was humorously critical of her social class during our interview explained, "For most women, no. These narratives of immediate success are just ridiculous to women. It drives most of us insane trying to keep up with them. Trying to perfect ourselves to this model of beauty and motherhood which isn't how it is at all. I am speaking from a place of privilege obviously, but I grew up in a single mother household. I know what it means to work hard and put everyone before yourself. My mother struggled much differently than I ever will." For Brooke, post-partum success had a lot to do with her resources and social class. She was aware of the privilege that comes with a high income lifestyle--to hire 
nannies, personal trainers, and buy healthy foods. On the other hand, several of the high income mothers did not seem aware of the extent to which their class privileges made it easier for them to make healthy choices and achieve post-partum bodies similar to their pre-baby ones.

Three of the higher income mothers interviewed were college professors who were more critical of CMB narratives. Samantha, a part-time professor and college admissions counselor, claimed she would not necessarily seek CMB narratives out; however they were in a lot of the magazines she reads and in some of the shows she watches on the weekends. Like many women, she showed some ambivalence towards her own consumption. She believed that because of her education she knew of the negative consequences and avoided comparing herself to them. However, she did say, "these women cannot be that perfect. It also makes me wonder exactly what these women are doing. I think a lot of them probably do more cosmetically than we think they do." She admitted that she was interested in what celebrity mothers do cosmetically, but because of her position and education, she did not believe cosmetic surgery was something worth pursuing. Jennifer, a professor and mother of three was very critical of CMB narratives and acknowledged the importance of education in challenging these narratives. She explained, "I think the more educated you are, I think the less likely you are to compare yourselves. At least that is the case for me. I want to look good...but I also know what society is trying to do by shoving these in my face. I know that these women have all the benefits in their life to help them be successful for looking good. These images are picked because they are the most flattering and best of these women. They aren't picking the worst pictures of them." I asked Jennifer if she thought women in academia were exempt 
from any negative effects of CMB narratives, and she responded, "We may not all be reading these magazines, but the headlines are everywhere. The guilt is everywhere. So we may know how socially constructed beauty is for example, but it doesn't mean we aren't subconsciously comparing and thinking critically of ourselves because of these." Another professor, Tiffany, reflected on the benefits of her education as well: "I certainly think these magazines want you to compare yourselves. It keeps you buying their magazines. I think with my education level, it keeps these images away from me. It doesn't influence me or my body image. I think okay, that's good for them...but I am also aware of social expectations and consumerism. I am just so trained with statistics to know about outliers and extremes, so I choose to overlook these." However, later in her interview while I showed her images of celebrity mothers she admitted, "It just looks that they have it all together more than I do. I know it is just a glimpse into their lives, but JUST enough to make me feel like I do not have it together. Their kids look good, they are all dressed up. And here I am not sleeping at night and barely getting my papers graded." These particular interviews with higher educated women suggested no mother is exempt from CMB narratives. Although these women are critical of these narratives and may not be actively reading or watching CMB narratives, they still hear about them - and are affected by them.

Interestingly, of all 25 women I interviewed, only the 10 high income mothers admitted to comparing themselves to women in their social circle in addition to the celebrity mothers. Because of their higher income bracket, these women displayed a sense of hyper-competitiveness among their friends and women in their social group. 
Miranda, the first higher income mother I interviewed brought this competitiveness to my attention:

For the social circle I am in, there is so much pressure to look good. I am surrounded by wealthy individuals, who know some of these celebrities. So I don't even have to pick up a magazine to compare myself to---I can just compare myself to my friends and the women at my country club. It's about the labels you are wearing and even what sports your kids are playing. Its hyper-competition at its finest. Even carpool! I pick up my kids and these moms get out of their cars in Lululemon outfits and their Gucci bags. I mean it is carpool people. What I am getting at is, I know these magazines are altered...so that is not as intimidating as when the people you are hanging out with are totally changing the way they look and flaunting it. The women I am surrounded by are the celebrities of this city. It is all relative. They may spend a week with the Kardashians and feel broke, but they aren't deprived.

Because these women were closer to the income brackets of some celebrity women, and often well-known individuals within their community, they found more pressure in competing with friends than with $\mathrm{CMB}$ narratives. For Miranda, keeping with other mothers in her social group was important. She seemed both envious of and overwhelmed by the effects of celebrity motherhood and the pressure to look good and appear rich. Unlike some of the other women interviewed, Miranda was very open about her lifestyle and anxieties that accompanied it, "I am envious. Even though we make good money...we don't make money like a lot of the families in this neighborhood. It is hard keeping up. So yeah, I wish I had all the tools to maintain the life they do and 
celebrity mothers do. They just seem so stressless." Similarly, Jennifer also said she compared herself to a lot of her rich friends because, "I found among my friends I can hold myself accountable to eat right and work out, so that I am keeping up with them." Another woman, Anne, who is a stay at home mother, explained, "the women I hang out with motivated me to want to look better and take care of myself after having my children. Most of my friends all lost weight pretty easily like me." I asked Anne if she thought it had anything to do with privilege to have assistance at home and own a gym membership. She replied, "maybe." This theme of comparison in social groups continued in my interview with Brooke, the sarcastic woman who was critical of her social status. "I compare myself to my friends and to the women I see every day in our social circles or in my job. I feel like there is much more pressure the higher your income is. There is just suddenly this expectation to look your best all the time. Even to go to tennis lessons or pick your son up from basketball. If I show up to his practice smoking and in my pajamas...the other mothers are going to start whispering. Isn't that just insane?' Brooke was both frustrated with and critical of the social expectations of those around her.

Each woman placed a huge emphasis on being physically fit. Additionally, all of the higher income mothers with the exception of three women had some form of Botox or cosmetic surgery to alter their bodies. Miranda remained critical of women in her social circles as well as the privilege of herself and CMB narratives, explaining, "I know a lot of people assume that women not getting back into shape is laziness. But I think getting into shape and to this extent in CMB narratives is insanely expensive. Yes I am well off, but I also work a lot. Most of the women in my circle do not. So the majority of their time is spent doing Pure Barre, Pilates, or personal training. There is also a lot of plastic surgery 
going on in this neighborhood. Even if you have the money it is a time commitment. So you REALLY have to have the set-up at home, and this just is not normal life for most women." Mothers like Caroline, Allison, and Brooke were very open about having plastic surgery, while Anne was embarrassed to admit having any work done. Anne whispered, "I had a tummy tuck. My friend used the same doctor and hers looked great, so I decided to do it." I asked why she whispered to me about her tummy tuck, she replied: "I know....and I don't understand why women don't talk about that more, ya know? I mean even among my friends, Plastic surgery is a secret. Weight loss efforts are a secret. Everyone has the better nanny or the better trainer. So and so has the better behaved children. Sometimes it just makes me crazy." On the other hand, Brooke admitted, "I worked my ass off to get in the shape I am. I also paid my doctor a lot of money to keep me looking this way. It was my choice, and I am very open about having plastic surgery and Botox. Most women are not. I see nothing wrong with keeping myself in shape and looking young." After asking Brooke about particular CMB narratives, she replied: "Look, I know that these women are being airbrushed and getting work done. Myself and my friends all get the same work done. For them it is a lot easier, because this is their career. They have to keep themselves in amazing shape in order to make it in the business. I know that I don't have to look like this in order to make it in my business, but in order to make it in my lifestyle and social circle yes I have to look a certain way."

Overall, the higher income mothers I interviewed felt immense pressure to look their best and keep up with friends and popular celebrity trends. Even if these women were critical of the hyper-competitiveness among themselves and their friends, they still felt it necessary. Most of these women see each other at parties, the pool, on vacations, 
school events for their children, and even at the gym. Thus, they are holding themselves and their bodies accountable to the expectations of both celebrity mothers and the mothers around them. The narratives of these high income women suggest that economic privilege may exacerbate the pressures reflected in $\mathrm{CMB}$ narratives - these women can afford to go to the extreme measures needed to "get one's body back" after childbirth.

\section{Low Income Mothers}

Of the women that I interviewed, 11 of them were low income mothers. These 11 young mothers attributed their inability to regain their pre-baby bodies to a lack of economic resources. Women ranged from age 19 to 45, were all single mothers, and found economic support from low wage jobs, their families or from social institutions like Family \& Education Support, an organization helping low income mothers obtain a college degree while giving childcare and financial support. Some of these women were unemployed, receiving welfare, full-time students, or working minimum wage jobs. Women interviewed were both Caucasian and African American. Many expressed a pattern of bad relationships which ultimately resulted in their pregnancies. All of these women turned out to be high consumers of celebrity motherhood, some more interested in the pregnancies, others more focused on celebrity post-partum narratives regarding weight loss. Initially these women expressed ambivalence towards CMB consumption, but once rapport was established, they began to divulge a pattern of high consumption. This suggests that the women might be experiencing a sense of embarrassment about sharing the extent to which they read or followed celebrity narratives of pregnancy and post pregnancy. The majority of these women were headline consumers-not willing to spend the money on purchasing popular magazines. However, all of these women 
admitted to going through these magazines or following CMB narratives on television and online.

These young mothers express powerlessness over their post baby bodies due to their lack of economic resources. They all describe the inability to "afford" the perfected body. In Prodigal Bodies, Cunningham argues that mediated images of celebrity motherhood celebrate the "prodigal body" of women who immediately get their bodies back. Further, CMB narratives are so prevalent that they have become the "paradigms of the ideal pregnant and post-pregnancy body" (Cunningham, 2). These women all noted that celebrities like Kourtney Kardashian, Jessica Alba, and Jennifer Lopez, were able to obtain a beautifully shaped and toned body quickly; and the low income mothers viewed their own post-baby bodies in a negative light. A young mother exclaimed, "these celebrity moms put so much pressure on people like me! Look at Kourtney Kardashian, who has 2 kids now and dropped the weight successfully in front of the public in a matter of weeks---it is almost like a slap in the face to normal women. Like hey! Look what I can do and you cannot. Especially for new moms, it makes us feel like we are alone. There are some women whose bodies bounce back, but most do not. Even if their weight goes back, their shape probably does not."

Mothers in this sample also compared their economic resources to those of celebrity mothers. Each woman made direct comparisons to celebrity mother's financial capabilities and surrounding support staff. The women observed that CMB obtained support from trainers, dieticians, and nannies that allowed them to focus solely on their body. Furthermore, they noted that it takes extensive financial resources to obtain this level of support. One mother, Ashley, who had her first child at the age of 14 declared 
that, "if you have money, this is what you look like. Without money, I do not think women's bodies are capable of looking like this immediately after pregnancy." Similarly, Leah claimed that she did follow celebrity mother's dieting and fitness advice, but said that they were more successful because, "they have nannies to help them. People like me, I don't have the time or the money for a personal trainer. I could diet, but that is hard also when you live a life financially struggling." Almost all of the low income mothers referred to themselves as "women like me" or "people like me," which showed a sense of class difference and awareness of the privileges women showcased in CMB narratives. Thus, these mothers were quite aware of the class privilege that undergirds the CMB narratives.

However, while critical of the class privilege of celebrity mothers, the low income mothers in this sample also wanted these economic privileges for themselves. For example, Kimberly, a single African American mother of three who was admittedly a major consumer of CMB narratives expressed her dreams of financial independence: "I know they have trainers and nutritionists, which us regular folks do not have. But by the time I decide to have a fourth child, I will be a dentist and can hire a personal trainer who can help me get back in shape." Despite her economic circumstances, she has a strong belief she can live the American dream like the celebrity mothers she follows in the media.

In addition to wanting the class privilege enjoyed by celebrity mothers, these low income mothers often expressed disappointment over their lack of economic resources; they often found their own lives and bodies lacking when compared to those of celebrity mothers. For example, Melissa, an African American mother of two expressed her 
frustrations with a culture obsessed with celebrity motherhood: "these celebrity women have the money, they have the means to achieve the look they want. These are all things I cannot do, and most women cannot do, because we do not have the same life." She expressed intense feelings of guilt and ambivalence towards her consumption of CMB narratives, admitting that too often herself and other women idolize celebrity mothers for their tiny toned bodies. "I know this is the body God blessed me with, but looking at these [images], I just feel fat. I feel like I need to lose more weight. They look fantastic...and I know they probably had people helping them look this way, so it is not totally realistic." She later went on to tell me, "I took advice from celebrity moms and tried to work out more and just drink water. But that didn't always work. I was stressed a lot and wanted chocolate." This particular mother showed a sense of powerlessness over her own body in regards to post-partum weight loss and CMB consumption. Like Kimberly, all of the low income mothers I interviewed had internalized feelings of guilt, inadequacy, and inability to control their own bodies by comparing themselves to socially constructed ideals of beauty and motherhood.

These women believe that their lack of financial resources is a major obstacle in attaining the hegemonic media construction of beauty and happiness. All women admitted to wanting plastic surgery if they had the money or their financial situations were different. Erica said, "I have thought about having plastic surgery on my stomach. Maybe in time I will have the money." Similarly, Candace said, "if I had the money, I would get a tummy tuck and breast-lift in a heartbeat!" Overall, these particular mothers acknowledged the privileges celebrity mothers have to improve their body cosmetically and wanted these same privileges for themselves. 
Some mothers felt powerlesss to change their circumstances even though they attributed their inability to regain their bodies to a lack of willpower. Even six years after giving birth to her daughter, one mother admitted that she still continues to follow CMB advice:

I have always followed Britney Spears. She would list her daily food regimen, like salmon rice and vegetables. That is not always realistic for women like me. I am a single mother and cannot afford all of the fancy and healthy foods all the time. Rather than to cook a healthy meal that costs 25 dollars with salmon and grilled chicken, I can take that money and buy food that will last all week. But it's not healthy, it is not what celebrity mothers are saying is right, or what mothers like me should be doing.

This indicated that it was a lack of access to economic resources and support that prevented low income mothers from obtaining good food, exercise programs, and dietitians. In essence, the low income mothers I interviewed were internalizing messages from media images that ensure a continued otherness.

Patricia Hill Collins argues that an "increasingly important dimension of why hegemonic ideologies concerning, race, class, gender, sexuality, and nation remain so deeply entrenched lies, in part, in the growing sophistication of mass media in regulating intersecting oppressions" (Collins, 284). Dominant groups control the images shown in popular magazines in order to commodify celebrity mothers and maintain a lucrative business (Echeveste, 2008). By comparing themselves to CMB narratives, these women believe that they are somehow faulty or different and thus experience feelings of powerlessness when comparing their experiences to celebrity mothers' experiences. 
Collins furthers this argument by claiming mass media shapes consciousness by manipulating images. For example, many of the low income mothers interviewed compared themselves to mass media's representations of motherhood. Melissa, a very religious mother of two who closely surveyed celebrity mothers in the media claimed "I compare myself to celebrity mothers a lot. I looked at Jessica Simpson who was struggling and joined Weight Watchers, thinking I could try to be successful like her I also joined. These women are financially fit and I am on the bottom. But I still felt like I could relate to them when I was pregnant." When pregnant, she could relate to celebrity women and their bodies, because it was okay to be big when pregnant; it didn't mean she wasn't successful. However, after having her baby, she had no excuse not to return to her pre-pregnancy weight. Melissa also looked into having a tummy-tuck done but admitted she was not financially able to do so. For this mother, success meant financially being able to support her weight-loss. In addition to joining Weight Watchers, she admitted to trying a water and salad diet based on advice from Kendra Wilkinson, and using diet tips from Beyoncé to count her calories. Thinness and getting her pre-pregnancy body back meant she could be successful like celebrity mothers. A strong emphasis has been placed on women's bodies in society where a woman's thin body equates her with beauty and social status (Malkin et al., 1999).

\section{Racial Difference and the Good Mother}

Out of the 25 women I interviewed, nine were women of color. These women acknowledged comparing themselves to $\mathrm{CMB}$ narratives showcasing Caucasian standards of beauty. These women clearly narrate their disjointed experience of comparing one's body to the CMB narratives produced in the hegemonic construction of white feminine 
beauty. The Caucasian standard of beauty seen in magazines is often referred to as, "tanned, healthy slenderness, with no unsightly bumps, bulges, or cellulite, and bodily and facial perfection that results from hours of labor: exercise, makeup, and hair care" (Khun, 1985). Other feminist theorists have defined Caucasian standards of beauty as thin, cosmetically enhanced, and highly sexual (Bordo, 1993; Wolf, 2002). Despite the fact that women are cognizant of the implications of CMB narratives, they still applied the framework of bodily perfection to their own post-partum bodies.

The cultural diversity of women in the United States is vast, yet there are few images in popular media that properly capture the experiences of motherhood for these women. Many researchers have addressed the exclusion of African American, Asian, and Latina mothers from historical narratives and popular media that defines American motherhood (Johnston \& Swanson, 2003; Collins, 1994). I would argue that CMB narratives also exclude women of color and promote hegemonic standards of beauty in celebrity mothers. For example, the women I interviewed were African America, Filipino, and racially mixed - and all mentioned the lack of racial diversity in motherhood models.

All of the magazines I collected from Winter of 2011 to February of 2013 were void of any African American CMB narratives. With the exception of Ebony, popular magazines and other mainstream forms of media almost exclusively showcase white beauty ideals. These women felt a clear disjuncture between the CMB narratives they were exposed to and their own personal experiences of body issues and motherhood. Without any depictions of female bodies and experiences similar to their own standpoint, these young women come to understand that society values the beauty and experience of 
Caucasian and light skinned celebrity women. This can be seen in my interview with Melissa, who could not understand why white celebrity women in CMB narratives were so successful and she was not. "Looking at these, I just feel fat. I feel like I need to lose more weight. They just look so fantastic, and I don't understand how they get their bodies so flat so soon. My hips could never be this size." Later in her interview she admitted that the main source of her body comparisons was to former Playboy Playmate Kendra Wilkinson, "I took her advice and did the salad and water diet. It was so hard for me to do. But that's my girl, so I kept trying and used her workout video also." Popular media and socially constructed ideals of beauty suggest that light skin, straight hair, and toned bodies are more desirable. In her book Unbearable Weight, Susan Bordo argues that societies' high standards of white feminine beauty can be problematic, "when Oprah Winfrey admitted on her show that all her life she had desperately longed to have "hair that swings from side to side' when she shakes her head, she revealed the power of racial as well as gender normalization, normalization not only to femininity, but to the Caucasian standards of beauty that still dominate on television, in movies, in popular magazines" (Bordo, 255). These mothers of color clearly recognize the Caucasian standards of beauty in the CMB narratives.

Paige, another African American mother of two stated "I've seen lots of pregnant women. I've been a pregnant woman twice...I just do not look like these women. The women I know do not look like that. These women are just so beautiful and perfect. Look at how tiny Kate Hudson is after having her kids." Several interviews later, another mother explained to me the importance of CMB narratives to her: "We all don't know what to do to lose weight but if you have women like this show you what to do...then 
maybe you can be successful." Thus, these women were internalizing images of successful post-partum weight loss seen in white CMB narratives and categorizing themselves as less than. Collins suggests that African American women learn to dislike their own bodies because of standards of beauty provided by mass media. The ultimate goal for these women was to achieve post-partum success that is depicted in CMB narratives which centers on white beauty standards, not African American beauty standards.

For the mothers of color I interviewed, this translated to a negative self-image and comparisons to a post-pregnancy body that would never be attainable for them. Importantly, the CMB they compared their own bodies against were images these mothers could not identify with racially or economically. The racially diverse celebrity mothers these women did identify with were all light skinned with chemically straightened hair (such as Beyoncé, Jennifer Hudson, Kimora Lee Simmons), and celebrity mothers from the shows Basketball Wives, and Real Housewives of Atlanta. One mother who was obviously aware of these representations of African American women in the media voiced her frustrations: "I don't think any of these women are good examples for black mothers. Even Jennifer Hudson, she totally forgot who she was. It is okay to be healthy and eat right to drop your baby weight, but she lost her black feminine curves." This implied that Hudson had lost what this mother identified as a sense of African American womanhood, only to take on a body that encapsulated the white hegemonic construction of beauty. Later in her interview, she went on to say that "these portrayals are just not realistic for black women. This is what influences eating disorders and women spending ridiculous amounts of money to have surgery on their bodies and 
change themselves." Her statement clearly concurs with what feminist journalist Lindsay Kite says in her article, Beauty Whitewashed: How White Ideals Exclude Women of Color, arguing that white standards of beauty for women of color is, "an objectified and unrealistic standard that is a nearly impossible combination for most women, unless extreme photoshopping or expensive and life-threatening cosmetic surgery is performed" (Kite, 2011).

Additionally, all nine mothers of color expressed concern over their stretch marks and how stretch marks were absent from white CMB narratives. Each woman of color interviewed mentioned a concern with their stretch marks in comparison with white CMB narratives. The absence of stretch marks in the images made them feel different and inadequate. A Filipino mother explained why she had such a negative self-image after having her daughter: "I have what I call tiger-stripe stretch marks. The coloring, everything about them grosses me out...and I feel like the women I see in these magazines are so absent of any flaws like this. They have flat, perfect skinned stomachs. It makes me think, what is wrong with me? My doctor said buying a cream wouldn't work for my type of skin. That I would probably have to have surgery." Although she was very critical of $\mathrm{CMB}$ narratives, these narratives still made her feel badly about herself.

I asked one mother, Ashley, to describe the difference in her skin to me. She said, "I am African American, so my weight gain affected my skin differently. I just wasn't comfortable with it. It looked like a raisin. The stretch marks are wide and discolored." Another mother admitted that she "absolutely hated" her body due to the dis-colored stretch marks she got in the last month of her pregnancy. These women were very 
concerned with the change in their bodies and skin color. Further, all nine women seemed very aware of self-difference and lack of representation in CMB narratives, making them believe celebrity pregnant bodies were not realistic models of motherhood for women of color. Based on these women's experience of scarring from stretch marks, I asked about the differences between stretch marks on white women and women of color. The women explained to me that African-American women tend to get stretch marks less often than other ethnicities, but the stretch marks may be more visible due to contrasting skin tones. Women of color had stretch marks that differed from the images of stretch marks in media and television.

The racially diverse $\mathrm{CMB}$ narratives these women did identify with were praised for good motherhood - meaning they had not actively been attacked in the media for bad parenting. Racially diverse celebrities who balance work and motherhood such as Beyoncé, Kimora Lee Simmons, Halle Berry, Alicia Keys, and Jennifer Hudson are all examples of successful women mentioned in interviews with women of color. Additionally, they were praised for a positive portrayal of black motherhood. For example, the mothers I interviewed believed celebrities like Beyoncé and Kimora Lee Simmons were good examples of African American women who have been successful at their careers and always cared responsibly for their children. One mother, Candace, mentioned Jada Smith claiming she had successfully "built a career and kept her children safe." Similarly, Leah noted that "Beyoncé stayed out of the media and protected her baby." The most important and consistent themes among the CMB narratives of color they mentioned were that all of these women had stayed out of trouble, avoided most public scrutiny, and raised their children privately. 


\section{CONCLUSION}

This research indicates the considerable influence of $\mathrm{CMB}$ narratives on women and suggests that these topics merit further research. CMB narratives placed immense pressure and guilt on the 25 non-celebrity mothers I interviewed. All the women, albeit to varying degrees, share the experience of feeling inadequate in the face of $\mathrm{CMB}$ narratives. Additionally, all 25 mothers thought men believed a woman's experience of pregnancy and post-partum body should mimic those of celebrities. No other research has firmly connected women's experiences to CMB narratives. Many have suggested $\mathrm{CMB}$ narratives could have a detrimental impact, but do not include any qualitative research using women's voices. This research uses the voices and experiences of women to show that $\mathrm{CMB}$ narratives are pervasive and problematic.

On average, the women interviewed consumed 3.4 hours of popular media sources, which they said overwhelmingly showcased CMB narratives. Many of these women considered this media consumption a guilty pleasure, while other women showed ambivalence towards their consumption, or subconsciously consumed CMB narratives. Despite the differences in levels of consumption, all women believed CMB narratives were problematic for women, as they normalized images of motherhood that were unrealistic for non-celebrity women.

The voices of the 25 women in this sample support several claims of the literature reviewed above: women tend to compare their own bodies to those of women in the media and most women view their bodies unfavorably after pregnancy (Gardner et al, 
1980; Martindale, 2012). Further, the CMB narratives these women compared themselves to represent a cultural ideal of thinness - one that feminists suggest creates unrealistic body images for women. Like women in other research, these women felt constant pressure to "get their body back" (Gardner et al., 1980; Wolf, 1991; Bordo, 1993; Dworkin \& Wachs, 2004). Although the majority of the 25 women interviewed seemed acutely aware of how these images have been stylized and airbrushed, they still admitted to viewing their bodies negatively in light of $\mathrm{CMB}$ narratives, and to comparing their pregnancies and post-partum bodies to those of celebrity mothers. Specifically, they were concerned with the effects CMB narratives had on themselves, future mothers, and young girls.

Higher income women framed motherhood in more competitive terms than other mothers, as the former were more concerned with living up to the perceived demands of mothers within their social standing. All 10 higher income women admitted they compared themselves to $\mathrm{CMB}$ narratives, and to women in their social circle. Douglas and Michaels (2004) argue that mass media's representation of motherhood has created an environment of hyper-competition, guilt and anxiety for women. Some women admitted to having plastic surgery in order to keep up with other mothers at their Country Club. This emulates Douglas and Michaels' belief that celebrity motherhood has developed into a culture of commodified competition which shames women into believing they need to be better than other women. Furthermore, when women compete against each other, this has a negative effect on their ability to organize for change.

Lower income mothers, while critical of the economic privileges held by celebrity mothers, nonetheless said they wanted those economic resources for themselves; most 
said they wanted the bodies of celebrity mothers, even if it meant engaging in plastic surgery to attain these bodies. While the low income mothers did not express motherhood in competitive terms (like the higher income mothers), they still wanted the economic privileges and the toned bodies shown in the CMB narratives. The lack of competition in these mothers' accounts could be because they saw CMB narratives as out of their reach; in contrast, the higher income mothers actually had the resources to attain the bodies presented in $\mathrm{CMB}$ narratives and felt more accountable to them.

The conventional socially accepted representations of motherhood in the media are those of middle- to upper-class white women. In a recent New York Times article, Kimberley Seals Allers, blogger and founder of MochaManual.com, a parenting Web site for African-Americans, addressed a lack of cultural appreciation for black motherhood, saying "even with a highly educated, modern black woman who is a self-described 'mom in chief' serving as the First Lady, black women are not included in any of the mainstream mommy dialogue in this country - which is dominated by white and affluent voices." Mothers are surrounded by homogenizing images which normalize dominant ideas of gender, race and class-one in which Douglas and Michaels says is the rich white celebrity mother. Further, mainstream media typically does not include the experiences of black mothers in its portrayals of motherhood because of a "long tradition of pathologizing black motherhood" (Allers, 2012; Douglas \& Michaels, 2004). Poor black women have been criticized and often demonized by politicians (and by white society more generally) as mothers whose reproductive choices jeopardize their children and society as a whole. Roberts analyzes the different narratives of black bodies used in society: Jezebel, Mammie, Black Matriarch, and the Welfare Mother. These "controlling 
images" can help explain why few positive images of black motherhood exist in CMB narratives.

The lack of positive and realistic images of black mothers in CMB narratives were noticed by the women of color in this sample. Each woman of color interviewed mentioned a concern with her stretch marks, and the absence of stretch marks on African American women's bodies in CMB narratives. My own search results for stretch marks among women of color found a complete absence of African American women's stretch marks in CMB narratives, feminist research, or even a simple Google search. This research suggests a need for further research on African American women's bodies. The women of color I interviewed were disproportionately low-wage earners, unlike most of the white women I interviewed. Thus, these women experienced motherhood in drastically different ways on social and economic levels. The upper income mothers in this research share very different experiences based on their class and education in comparison to the low-income women who were disproportionately women of color. Higher income mothers were all white women who had abundant resources available to them such as nannies, personal trainers, and the ability to afford cosmetic surgery. In contrast, lower income mothers did not have these resources. Consistent with an intersectionality perspective (Collins, 1994; Roberts 1997), this shows that race and class intersect to create distinctive experiences of motherhood.

The social construction of motherhood in the 1950's, which over time developed into a cultural obsession with celebrity pregnancies, has perpetuated the mask of motherhood, the socially constructed notion that motherhood is a universal experience of happiness, and the most important thing a woman will ever do. This research shows that 
in suggesting that all women should strive to conform to unrealistic post-partum bodies, CMB narratives serve as a more current form of the mask of motherhood (Rich, 1976; Friedan, 1983; Maushart,1999). In addition, these narratives present a universal experience that lacks diversity in race/ethnicity, income, and education. In Making Sense of Motherhood: A Narrative Approach, Miller (2005), argues that women should not consider motherhood to be a universal experience, because all women experience motherhood differently. I would argue that the universalizing nature of CMB narratives are problematic for non-celebrity mothers, who internalize feelings of guilt, inadequacy, and negative self-images when comparing themselves to CMB narratives. Despite these women's diverse backgrounds, all agreed that CMB narratives had lasting negative effects, both mentally and physically.

There is a lack of feminist research on how women are directly affected by these depictions and how their reactions to these depictions might vary by their educational, social class, and racial backgrounds. It is vital to look at motherhood through an intersectional lens, because not all women are white, middle class mothers who have the resources to look and mother like women illustrated in CMB narratives. This research is the first study to look at the different experiences of mothers in light of CMB narratives. Although the sample of women for this research is limited to a moderately-sized, Midwestern city, given the national market of $\mathrm{CMB}$ narratives, there is reason to believe these dynamics occur in other areas of the country. Further research is needed in stretch mark differences among women of color, as well as a greater sample of women given the lack of higher income women of color and lack of Latina women. Overall, this research is important in understanding women's experiences. This research embodies the goals of 
feminist research—to foster empowerment for women, to document women's experiences that have not been voiced, and to challenge structures that oppress women.

Lastly, I would argue that this research itself can serve as a form of consciousness- raising among mothers. Many mothers in this sample strongly believed that providing and discussing more accurate representations of motherhood is important for change. Many of the women commented on a lack of dialogue among mothers concerning their expectations and experiences with pregnancy and post-partum weight loss. It seems that if women were more open and honest with each other about their own feelings of guilt and inadequacy in the face of CMB narratives, this could lead to less competition among higher income mothers, and more solidarity among lower income mothers. This could pave the way for more challenges to CMB narratives. In addition, women in this sample with higher levels of education were generally more critical of $\mathrm{CMB}$ narratives; this suggests that higher education can help women challenge these pervasive narratives. If popular magazines and women's media are really women's magazines, it is important that a shift is made towards diverse representations of women. Given that a universal narrative for the pregnant and postpartum experience does not exist, women should pressure media to explore narratives from the standpoints of women of color and from the standpoints of women with different class backgrounds. It is vital for women to deconstruct the hegemonic narrative of celebrity mothers' pregnant and postpartum experience to prevent negative consequences for both this generation of mothers and mothers in future generations. 


\section{REFERENCES}

Allers, Kimberly Seals. (2012). "Hollywood to Black Mothers: Stay Home." The New York Times. 18 June.

Balsamo, Anne Marie. (1996). Technologies of the Gendered Body: Reading Cyborg Women. Durham: Duke UP.

Bordo, Susan. (1993). Unbearable Weight: Feminism, Western Culture, and the Body. Berkeley: University of California.

Bernstein, Jacob. (2012). "The Baby Bump." The New York Times, Section: STI, 29 Apr.

Chambers, Deborah. (2009). The Flaunting of Fertility: Popular Media Representations of the Maternal. Thesis. Newcastle University, UK.

Collett, J. L., (2005). "What kind of mother am I? Impression Management and the social construction of mothering”, Symbolic Interaction, Vol. 28, No. 3, pp. 327-247.

Collins, Nancy. (1991). "More Demi Moore." Vanity Fair Aug.

Collins, Patricia Hill. (2004). Black Sexual Politics: African Americans, Gender, and the New Racism. New York: Routledge.

Collins, Patricia Hill. (1994). "Shifting the Center: Race, Class, and Feminist Theorizing about Motherhood." Mothering: Ideology, Experience, and Agency. New York: Routledge, 4564.

Cunningham, Hilary. (2002). "Prodigal Bodies: Pop Culture and Post-Pregnancy." University of Michigan Library XLI.3: 1-13.

Davis, Angela. (1991). "Outcast Mothers and Surrogates: Racism and Reproductive Politics in the Ninties." Feminist Reader: A Reader . 509-15. 
Douglas, Susan J., and Meredith W. Michaels. (2004). The Mommy Myth: The Idealization of Motherhood and How It Has Undermined Women. New York: Free.

"Dropping Post-Pregnancy Pounds." (1992). Redbook. Volume 179/4. 01 Aug.: 33.

Dworkin, S. L., and F. L. Wachs. (2004). "Getting Your Body Back": Postindustrial Fit Motherhood in Shape Fit Pregnancy Magazine." Gender \& Society 18.5: 610-24.

Echeveste, Stephanie. (2008). Baby Bumps to Silver Screen Preggos: Commodity Pregnancy in a Postfeminist Context. Thesis. University of Southern California.

Faludi, S. (1991). Backlash: The undeclared war against American women. New York: Crown. Fox, Pauline, and Chryseus Yamaguchi.(1997). "Body Image Change in Pregnancy: A Comparison of Normal Weight and Overweight Primigravidas." Birth 24.1: 35-40.

Fredrickson, Barbara L., and Tomi-Ann Roberts. (1997). "Objectification Theory." Psychology of Women Quarterly 21.2: 173-206.

Friedan, Betty. (1983). The Feminine Mystique. New York: Norton.

Garder, David; Schwartz, Donald; \& Thomoson, Michael. Cultural Expectations of Thinness in Women (1980). Psychological Reports: Volume 47, Issue , pp. 483-491.

Gentile, Katie. (2011). "What About the Baby? The New Cult of Domesticity and Media Images of Pregnancy." Studies in Gender and Sexuality 12: 38-58.

Guzman, Isabel, and N. Valdivia. (2004). Brain, Brow, and Booty: Latina Iconicity in U.S Popular Culture. The Communication Review 7: 205-221.

Hays, Sharon. (1996). "The Mommy Wars: Ambivalence, Ideological Work, and the Cultural Contradictions of Motherhood." The Cultural Contradictions of Motherhood. New Haven: Yale UP.

Hopper, Megan, and Jennifer Stevens Aubrey. (2011). "Examining the Impact of Celebrity Gossip Magazine Coverage of Pregnant Celebrities on Pregnant Women's SelfObjectification." Communication Research : 1-22. 
Jerkin, W., \& Tiggemann, M. (1997). Psychological effects of weights retained after pregnancy. Women and Health, 25(1), 89-98.

Johnson, S., Burrows, A., \& Williamson, I. (2004). "Does this make my bump look big in this?" The meaning of bodily changes for first-time mother-to-be. Journal of Health Psychology, 9(3) 361-374.

Johnston, Deirdre D., and Debra H. Swanson. (2003). "Invisible Mothers: A Content Analysis of Motherhood Ideologies and Myths in Magazines." Sex Roles 49.1/2: 21-33.

Kaiser, S. B. (1997). The social psychology of clothing. (2nd ed.). New York, NY: Fairchild Publications.

Kasle, Jennifer. (1997). "Pretty in Pregnancy." Redbook Nov: 47-49. Volume 190/1.

Kilbourne, Jean. (1999). Deadly Persuasion: Why Women and Girls Must Fight the Addictive Power of Advertising. New York, NY: Free.

Kite, Lindsay. (2011). "Beauty Whitewashed: How White Ideals Exclude Women of Color."

Malkin, Amy R., Kimberlie Wornian and Joan C. Chrisler. (1999). "Women and Weight: Gendered Messages on Magazine Covers.” Sex Roles 40:647-55.

Marikar, Sheila. (2011). "Mariah Carey's Massive Post-Pregnancy Weight Loss." ABC News, 9 Nov. Web. <http://abcnews.go.com/blogs/entertainment/2011/11/mariah-carey-drops-30pounds-post-pregnancy/>.

Martindale, Addie. (2012). The Pregnant and Postpartum Body as Constructed in People Magazine, 2000-2007: A Content Analysis. Thesis. Colorado State University.

Maushart, Susan. (1999). The Mask of Motherhood: How Becoming a Mother Changes Everything and Why We Pretend It Doesn't. New York: New.

Meyers, Diana Tietjens.(2001). "The Rush to Motherhood: Pronatalist Discourse and Women's Autonomy." Signs: Journal of Women in Culture and Society 26.3: 735.

McMahon, M. (1995). Engendering Motherhood: Identity and Self-Transformation in Women's Lives, New York, The Guilford Press. 
McRobbie, A. (2006). "Yummy mummies leave a bad taste for young women", The Guardian, 2 March, last accessed online, $17 \mathrm{July,} 2008$.

Min, Janice. (2012). "Can a Mom Get a Break?" The New York Times 19 Aug., Section: ST1.

Miller, Samantha. (1997). "Ma-Ma-Ma-Vooom." People 26 May: 83-86. Volume 47/20.

Miller, Tina. (2005). Making Sense of Motherhood: A Narrative Approach. Cambridge: Cambridge UP.

Morris, T. and McInerney, K. (2010), Media Representations of Pregnancy and Childbirth: An Analysis of Reality Television Programs in the United States. Birth, 37: 134-140.

Nash, Meredith. (2005). "Oh Baby, Baby: (Un)Veiling Britney Spears' Pregnant Body." Bodies: Physical and Abstract 19.

Narayan, U. (1997). Contesting cultures: "Westernization," respect for cultures, and third-world feminists. In: Second Wave: A Reader in Feminist Theory, ed. L. Nicholson, New York, NY: Routlege, pp. 396-414.

O'Donohoe, S. (2008), "Yummy Mummies: The clamor of glamour in advertising to mothers", Advertising and Society Review, Vol. 7, No. 3.

Oliver, Kelly. (2010). "Motherhood, Sexuality, and Pregnant Embodiment: Twenty-Five Years of Gestation." Hypatia 25.4: 760-77.

Pincus, Jane. (2010). "Laboring Under an Illusion: Mass Media Childbirth vs. The Real Thing." Wiley Online Library 37.1: 82-83.

Powell, Joanna. (1994). "Sela's Baby Jitters." Redbook May: 81-84.

Rich, Adrienne. (1976). Of Woman Born: Motherhood as Experience and Institution. New York: Norton.

Roberts, Dorothy (1997). E. Killing the Black Body: Race, Reproduction, and the Meaning of Liberty. New York: Pantheon.

Thurer, Shari. (1994). The Myths of Motherhood: How Culture Reinvents the Good Mother. Boston: Houghton Mifflin. 
Tyler, I., (2001) ' Skin-tight: Celebrity, Pregnancy and Subjectivity' in Ahmed, S., and Stacey, J., eds. Thinking Through the Skin, Routledge: London and New York, 69-83.

Wolf, N. (1991). The Beauty Myth: How images of beauty are used against women. New York: Morrow. 


\section{CURRICULUM VITAE}

NAME: Brittany Marie Williams

ADDRESS: 1508 Cadet Ct.

DOB: $\quad$ Louisville, Kentucky - March 1, 1987

EDUCATION

\& TRAINING: M.A. Women's and Gender Studies

University of Louisville, 2013

B.A. Political Science, minor in Sociology

Bellarmine University, 2010

AWARDS: Mary K. Bonsteel Tachau Scholarship

University of Louisville, 2011

Women in Leadership Conference Nominee

Bellarmine University, 2008

Kentucky Women's Bluegrass Political Apprenticeship

Bluegrass Alliance for Women, 2008

PROFESSIONAL SOCIETIES: Graduate Student Union Representative

University of Louisville, 2012-2013 